ORIGINAL RESEARCH

\title{
Femoral Traction Splints in Mountain Rescue Prehospital Care: To Use or Not to Use? That Is the Question
}

\author{
Harriet Runcie, MB ChB; Mike Greene, FRCS, FCEM \\ From the North Cumbria University Hospitals NHS Trust, Emergency Department (Dr Runcie), and Emergency Medicine (Mr Greene), \\ West Cumberland Hospital, Whitehaven, UK.
}

\begin{abstract}
Objectives.-To determine the incidence of femur fractures in mountain rescue in England and Wales. To investigate the attitudes of rescuers toward the use of femoral traction splints. To review the literature for evidence on the use of traction splints in prehospital medicine and test the hypothesis that femoral traction splints reduce morbidity and mortality in patients with a fractured femur.

Methods.- The Mountain Rescue England and Wales database was searched for cases of suspected fractured femur occurring between 2002 and 2012, a questionnaire was sent to all mountain rescue teams in England and Wales, and a literature review was performed. Relevant articles were critically reviewed to identify the evidence base for the use of femoral traction splints.

Results.-Femur fractures are uncommon in mountain rescue, with an incidence of suspected femur fractures on scene at 9.3 a year. Traction splints are used infrequently; $13 \%$ of the suspected femur fractures were treated with traction. However, rescuers have a positive attitude toward traction splints and perceive few disadvantages to their use. No trials demonstrate that traction splints reduce morbidity or mortality, but a number describe complications resulting from their use.

Conclusions.-Femur fractures are rare within mountain rescue. Traction splints may be no more effective than other methods of splinting in prehospital care. We failed to identify evidence that supports the hypothesis that traction splints reduce morbidity or mortality. We advocate the use of a femoral traction splints but recognize that other splints may also be appropriate in this environment.
\end{abstract}

Key words: femoral fracture, splints, traction, wilderness medicine, prehospital care

\section{Introduction}

The first femoral traction splint was designed in 1875 by Hugh Owen Thomas for the treatment of chronic joint problems, in particular tuberculosis of the knee. ${ }^{1}$ During the First World War, Dr Jones introduced femoral traction splints into military practice. ${ }^{2}$ They became the standard definitive treatment for femur fractures until the development of femoral nailing in the 1950s. From the 1980s onward, femoral nailing became the definitive treatment and traction splints were only used before

Disclaimers: The authors have no financial ties to disclose. This study has been discussed with the U.K. NHS Research Authority Research Ethics Committee. No concerns were identified and it was deemed further review was not required. M.K. Greene is Medical Officer for Mountain Rescue England and Wales and a member of The International Commission for Alpine Rescue Medical Commission.

Corresponding author: Harriet Runcie, MB, ChB, North Cumbria University Hospitals NHS Trust, Emergency Department, West Cumberland Hospital, Whitehaven, CA28 8JG (e-mail: harriet.runcie@ gmail.com). surgery. ${ }^{3}$ Traction splints are believed to reduce the complications of a femur fracture: bleeding, pain, and nerve damage. They are regarded as standard treatment for the initial management of fractures of the shaft of the femur in prehospital care and are advocated in prehospital care and mountain medicine texts both in the United Kingdom and the United States. ${ }^{4-9}$

In the challenging environment of mountain rescue, traction splints can be difficult to use. They require training and may not fit into the package of stretcher, casualty bag, and vacuum mattress. In addition, they have to be carried to the scene and can only be used for a single type of injury.

This study was designed to investigate the strength of literature supporting the use of femoral traction splints and the attitudes of rescuers who use them. The incidence of these fractures in mountain rescue in England and Wales has not been previously reported. This study has relevance to all those in prehospital care and in particular to those who practice wilderness medicine. 


\section{Methods}

Mountain Rescue England and Wales (MREW) maintains a database of all calls undertaken by mountain rescue teams within England and Wales. It contains details on the incident, the casualty's injures, and treatment. This database was searched using the search criteria "fractured femur" for cases between April 2002 and April 2012. To investigate attitudes toward traction splints, a questionnaire was designed (Appendix 1) and posted on a website. An e-mail containing a link was then sent to all England and Wales mountain rescue teams secretaries, who were asked to distribute it to all their team members. Participants were offered a range of problems and benefits on the use of traction splints and asked to rank them on perceived importance. A literature search was performed using Embase, Medline, and Cochrane databases. Multiple searches were performed using various search terms: "femur OR femoral fracture AND traction splints," "traction splints," "complications AND traction splints," and "benefits AND traction splints." These were combined with other searches using the terms "prehospital medicine" and "femur OR femoral OR shaft of femur AND fracture." The identified articles and any relevant referenced articles were critically reviewed and graded according to quality, using the Oxford Centre for Evidence-Based Medicine tools. ${ }^{10}$

\section{Results}

During the 10-year study period, 93 casualties with a suspected femur fracture were identified (9.3 per year). These injuries were identified by the mountain rescue team members and included all clinically suspected femur fractures. It was recorded in the database that $13 \%$ of the suspected femur fractures had been treated with a traction splint, $17 \%$ with a simple splint without traction, and $70 \%$ without any kind of limb splint.

A questionnaire was sent out to all MREW teams to assess attitudes toward traction splints. Responses were received from 26 of the 51 teams, a total of 164 individuals. Responses came from all regions of the United Kingdom covered by the MREW teams. In this survey $44 \%$ of team members reported that they had not encountered a femur fracture or used a traction splint in the past 5 years. Figure 1 demonstrates all the estimates given.

When asked about use, $68 \%$ of rescue team members who responded reported using a traction splint for every suspected femur fracture, $32 \%$ said they used a traction splint selectively and decisions were based on the type of fracture, the other associated injuries, availability of splints, and other forms of analgesia. Ninety-three percent of team members reported having had training on traction splint use within the past year, with $75 \%$ of those within the last 6 months.

The survey assessed attitudes toward the perceived benefits and problems of using a traction splint in this environment using a numerical rating scale, where 1 was not beneficial/not problematic and 5 very beneficial/very problematic. The results were generally positive, with most team members perceiving suggested benefits at 5 (very beneficial; Figure 2), and the problems low, suggesting little difficulty in using traction splints (Figure 3).

The literature search initially found 141 articles. These were looked at to assess whether they helped disprove the hypothesis that traction splints reduce morbidity and mortality of femur fractures. Of these 141 articles, we identified 17 plus 1 conference abstract relevant to the hypothesis. Of these, 4 were excluded: 2 because they discussed traction splint use as a definitive treatment before the introduction of femoral nailing or in children, and a further 2 because they were designated as level 5

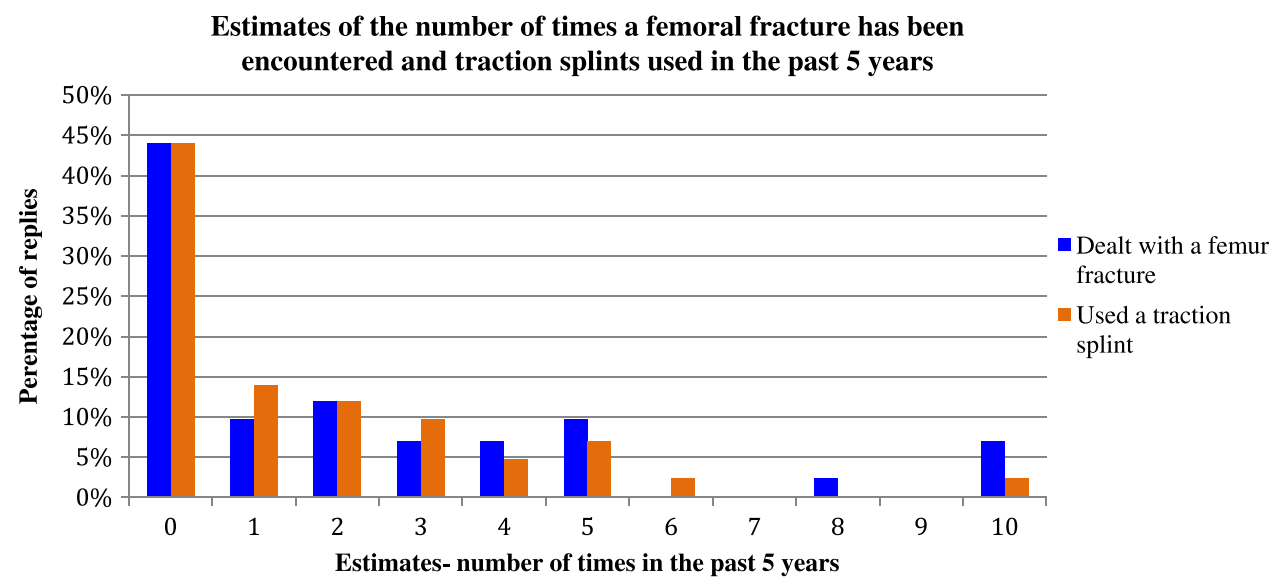

Figure 1. Estimates on femur fracture encounters and on use of traction splints. 


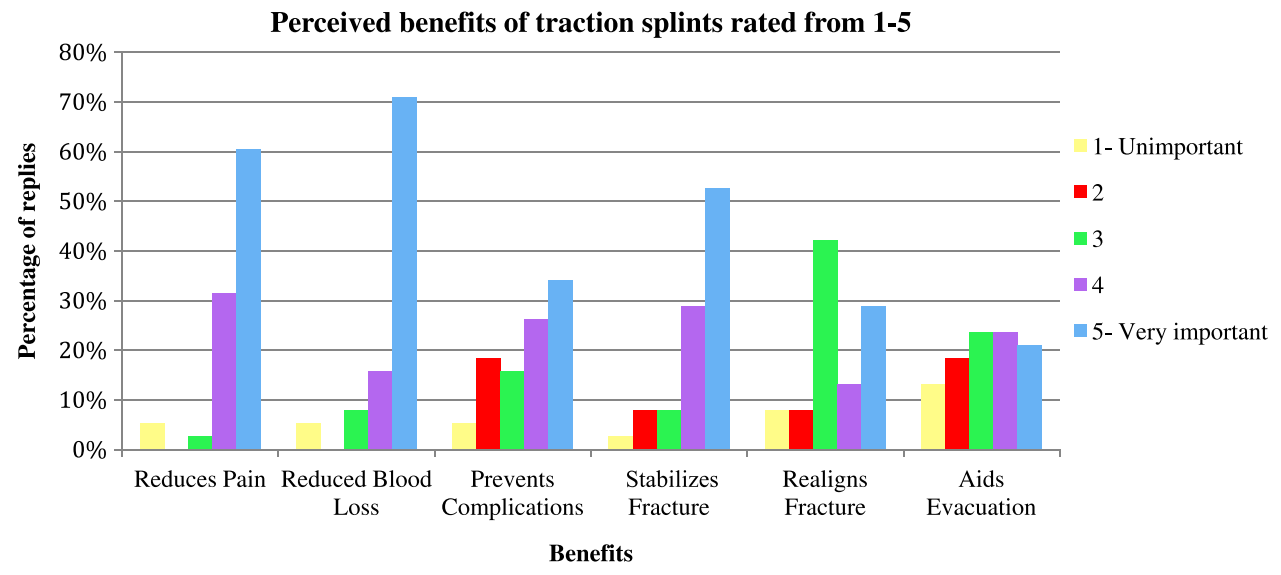

Figure 2. Perceived benefits.

quality according to the evidence-based medicine tool, lacking detailed information on where the opinions and stated facts within the articles had originated. A further 4 discussed the history of the traction splint (Appendix 2). There were 4 articles that described single case studies with complications directly caused by traction splint use. Complications included pressure sores,${ }^{11}$ compartment syndrome, ${ }^{12}$ peroneal nerve palsies, ${ }^{13}$ and urethral injury. ${ }^{14}$ Five articles discussed traction splint use, drawn from the literature or case studies (Table). ${ }^{11,15-18}$ These 5 concluded that traction splints may not be beneficial.

\section{Discussion}

We suspect that an incidence of 9.3 femur fractures in the England and Wales mountain environment per year is an overestimate. It is unlikely any femur fractures were clinically missed by the rescue teams; however, other soft tissue thigh injuries could have been mistaken for a fracture and included in the data, which records the clinical diagnosis made on scene. Nevertheless clinical suspicion of a fracture in the prehospital setting demands treatment for the suspected injury. It was not possible to separate neck of femur fractures from shaft of femur fractures in the database search, and these would not normally be treated with a traction splint. However, the mean age of casualties in the database was 38 , and the total number of cases older than 70 years was 11 . Thus, given that neck of femur fractures are usual in older people, it is likely on average only about 1 case per year was a neck of femur fracture. To obtain the exact incidence within mountain rescue, the mountain rescue database

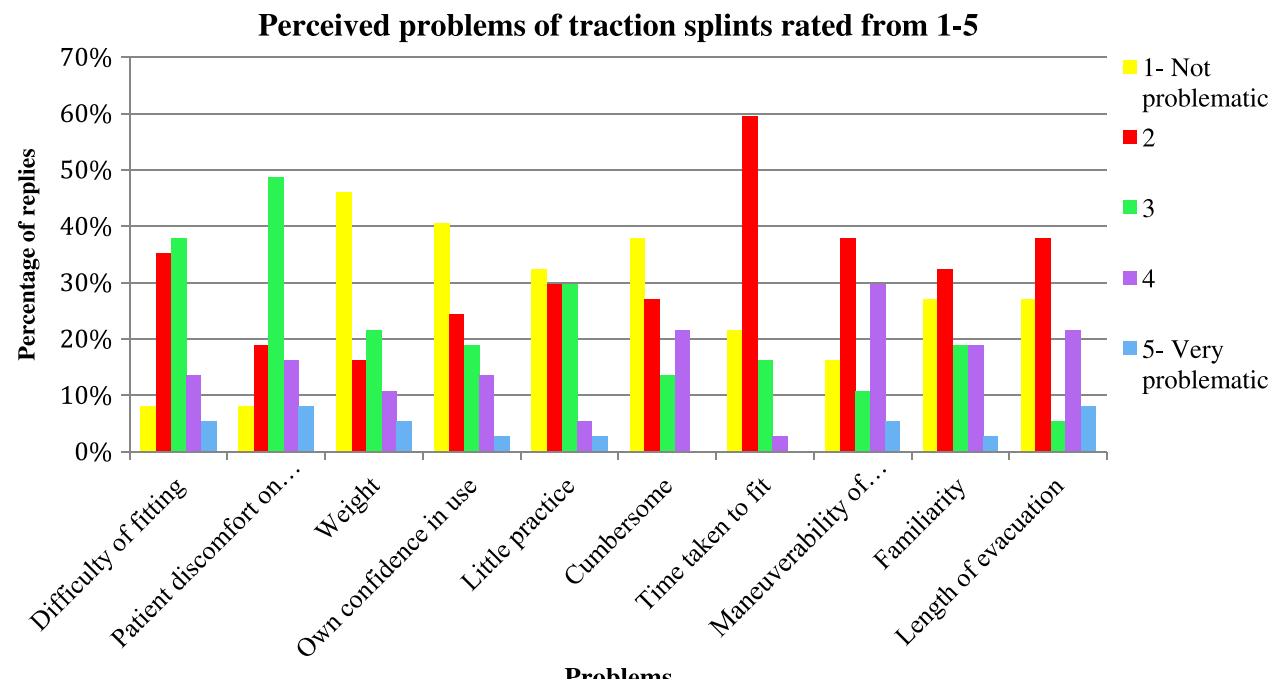

Figure 3. Perceived problems. 
Table. A summary of the 5 articles in the literature reviewing traction splint use

\begin{tabular}{|c|c|c|c|}
\hline Reference & Outcomes & Study weaknesses & Level of evidence \\
\hline Ellerton et al. ${ }^{18}$ & $\begin{array}{l}\text { No evidence for best methods } \\
\text { for managing femoral } \\
\text { fractures. Advise femoral } \\
\text { traction splint or simple } \\
\text { vacuum mattress/box splint. }\end{array}$ & $\begin{array}{l}\text { A generalized look at splinting. } \\
\text { Little detail on femoral } \\
\text { fractures. Limited available } \\
\text { literature. }\end{array}$ & $\begin{array}{l}\text { Literature review of mainly } \\
\text { case series studies. Level } 4\end{array}$ \\
\hline Agrawal et al. ${ }^{11}$ & $\begin{array}{l}\text { Little evidence for use of } \\
\text { femoral traction splints. }\end{array}$ & $\begin{array}{l}\text { A case presentation with } \\
\text { discussion of literature. } \\
\text { Limited available literature. }\end{array}$ & $\begin{array}{l}\text { Case presentation with } \\
\text { literature review based on } \\
\text { case studies. Level } 4\end{array}$ \\
\hline Wood et al. ${ }^{15}$ & $\begin{array}{l}38 \% \text { of patients with traction } \\
\text { splints fitted had } \\
\text { contraindications. Simpler } \\
\text { methods of immobilization } \\
\text { may prove safer and equally } \\
\text { efficacious. }\end{array}$ & $\begin{array}{l}\text { No follow-up or review of } \\
\text { outcome. Unknown whether } \\
\text { contraindications had an } \\
\text { adverse effect. }\end{array}$ & Case series: 40 cases. Level 4 \\
\hline Bledsoe and Barnes ${ }^{17}$ & $\begin{array}{l}\text { Femur fractures are rare, and } \\
\text { owing to contraindications } \\
\text { traction splints are rarely } \\
\text { used. A review of guidelines } \\
\text { needed; perhaps ambulances } \\
\text { do not need to carry a } \\
\text { traction splint. }\end{array}$ & $\begin{array}{l}\text { Conclusions based on only } 4 \\
\text { case studies. No information } \\
\text { on search criteria and } \\
\text { inclusion/exclusion of } \\
\text { studies. }\end{array}$ & $\begin{array}{l}\text { Review of literature based on } \\
\text { case studies. Level } 4\end{array}$ \\
\hline Abarbanell $^{16}$ & $\begin{array}{l}\text { Of } 4513 \text { paramedic calls over a } \\
\text { year, } 5 \text { had suspected femur } \\
\text { fracture. Of those } 5,2 \text { had } \\
\text { traction splints fitted } \\
\text { successfully. }\end{array}$ & $\begin{array}{l}\text { Conclusions based on only } 5 \\
\text { cases. No details of follow- } \\
\text { up, complications, and } \\
\text { outcomes. }\end{array}$ & $\begin{array}{l}\text { Observation study of } 5 \text { cases, } \\
\text { no follow-up. Level } 4\end{array}$ \\
\hline
\end{tabular}

would need to include the definitive diagnosis made after hospital assessment and radiological investigation.

The number of femur fractures in mountain accidents has been identified in other literature. Hearns ${ }^{19}$ reviewed accidents in the Scottish mountains during a 2-year period. There were 333 casualties of which 261 had traumatic injuries. Of these, 50\% had lower limb injuries, but the number of fractured femurs is not recorded. This paper identified only 12 patients with an Injury Severity Score (ISS) greater than 15, and none of these had a fractured femur. There were 57 deaths, of which 1 died as a result of a hemorrhage secondary to an open fractured femur. Goel and Addison ${ }^{20}$ published a series of patients who attended a Cumbrian Hospital after injury in the Lake District mountains. During 3 years, 90 patients were identified, of whom 2 had a fractured femur. In a 2-year review of alpine falls in Europe by Hohlreider et al, ${ }^{21}$ there was 1 femur fracture in a series of 97 surviving patients. Our result therefore adds to the information available on mountain accidents and appears to be in keeping with other studies, which also found femur fractures are rare events.

This study suggests a mountain rescue team in England and Wales will encounter a casualty with a femur fracture on average every 6 to 7 years. This correlates with the questionnaire, in which $44 \%$ of team members had not encountered any femur fractures in the past 5 years. It is skewed among teams, however, with some teams-those in North Wales, the Lake District, and Yorkshire in particular-seeing femur fractures more frequently than the others. The reason may be the frequency of calls and the nature of the terrain, with these teams operating in high mountainous environments a long way from habitation yet also operating in national parks with high numbers of visitors.

It is of interest that only $13 \%$ of cases recorded in the database were treated with a traction splint and $70 \%$ with no splint at all, but in the questionnaire most rescuers reported always using a traction splint for suspected femur fractures. The reasons for the discrepancy between this perception and the database are not known. However, the database is a record of events whereas the questionnaire responses are estimates and perceived ideas. Forty-four percent of rescuers also reported not having encountered a fractured femur in the past 5 years, so thinking back longer than that to recall what was actually done is difficult and likely to be unreliable. Perhaps the rescuers believe they should be using the 
traction splint for every fracture, but in practice, despite believing them to be useful, considered it to be an unsuitable tool for the situation at that specific time. The rescuers, of course, should not always be using traction as contraindications may exist. There could also be an error in data collection, with rescuers not recording a vacuum mattress as a splinting device.

Mountain rescue teams have infrequent opportunities to use a femoral traction splint. This study shows that all teams own one and usually carry it out to casualties when a femur fracture is suspected. From the questionnaire it was evident that team members thought of the splint as a useful tool, believing it to reduce the complications of a femur fracture, and they reported that generally they did not have any difficulties in using traction splints. This is likely to be a result of the teaching they receive and the practice advised in current guidelines, rather than from personal experience.

We found very little evidence supporting the use of prehospital traction splints in the literature. There are no published trials demonstrating that a traction splint reduces bleeding and other complications of a femur fracture.

The original evidence promoting traction splint use comes from Dr Henry Gray, who, in a book about war wounds written in 1917, noted that the death rate from gunshot femoral injury was around $80 \%$ but that during one battle the death rate fell to $15 \%$ when most casualties were fitted with the Thomas splint. ${ }^{22}$ But as Henry and Vrahas $^{23}$ point out, this statement does not mean traction splints reduced mortality from $80 \%$ to $15 \%$, as some articles have suggested. There were many other advances in medicine during that period that could account for the reduction in death rate. In particular, specialized orthopaedic clearing stations were developed so early treatment could be provided on the edge of the battlefield. We now understand that changes to a system of trauma care can have significant effects on outcome. There were also advances in the management of wounds and the development of antiseptics. The Thomas splint provided stabilization of the fracture while also allowing access for treatment of the wounds, reducing the risk of septicemia. This is still an important element of care for military open femoral fractures. ${ }^{24}$ No other articles were found that demonstrated that traction splints reduce the complications-pain, bleeding, or nerve injury-of femur fractures.

Five articles discuss traction splint use, either from reviewing the literature or after discussing case reviews (Table). Wood et $\mathrm{al}^{15}$ looked at 40 cases in which a traction splint had been fitted, then reviewed the radiographs. They found that $38 \%$ of patients had contraindications to traction use, most commonly a concomitant pelvis fracture. They therefore concluded that simpler methods of immobilization with fewer complications may prove safer and equally effective, and when contraindications exist, the traction splints should be avoided. However, they did not follow up the patients nor look at outcomes, so it is not known whether any adverse outcome occurred in these patients fitted with traction splints when contraindications existed.

Abarbanell ${ }^{16}$ looked at the prehospital management of femur fractures by paramedics, reviewing 4513 paramedic calls during a year. Of those there were 5 suspected femur fractures, and a traction splint was fitted successfully only twice. For the other 3 cases, one had a contraindication (hip injury), a second was transported in a position of comfort, and the third had severe pain on fitting of the splint. There was found to be no sequelae resulting from the different methods of care; however, time scales for follow-up are unclear and outcomes are not detailed. Abarbanel1 ${ }^{16}$ also suggests that owing to the rarity of femur fractures, traction splints in ambulances may be unnecessary and that transporting patients on long backboard immobilization, rigid splint, or in a position of comfort may be acceptable care. Bledsoe and Barnes ${ }^{17}$ suggest that because of the risk of complications with traction use, the number of contraindications, and particularly the rarity of femur fractures, ambulances and rescue vehicles may not need to all carry traction splints. Both these articles are based on a small number of cases, there are no comparisons or controls or information on follow-up, and they make suggestions based on the rarity of femur fractures that they both agree need further research to confirm. We believe in delivering evidence-based best care; the frequency of encountering the injury should not be a factor in considering whether or not to use a particular form of splint.

Ellerton et al, as part of the International Commission for Mountain Emergency Medicine, ${ }^{18}$ performed a detailed literature review on immobilization and splinting of fractures, with femoral fractures making up only a small part. They produced guidelines recommending either a femoral traction splint or a simple vacuum mattress after manual traction for the management of femoral fractures, as no studies were identified that could be used to recommend optimal management. Agrawal et $\mathrm{al}^{11}$ present a case study of a complication after the use of a traction splint and then discuss the available literature, mainly historical evidence plus single case studies of complications. They conclude that there is little evidence that use of the traction splint is more efficacious than simple, rigid, well-padded splints, pillow splints, or a Jones's bandage. These 2 articles set out the most detailed review of the 
current literature, but both conclude there is not enough evidence on which to make decisions.

The most recent article published is an abstract and poster from a conference. ${ }^{25}$ Spano et al looked at 579 cases of midshaft femur fracture. Their results on traction splint use are similar to those set out in this article, with $30 \%$ having a prehospital traction splint fitted, whereas $70 \%$ did not. Interestingly those with a higher ISS were more likely not to have a traction splint fitted. They found that there was no significant difference in complication and mortality between the 2 groups.

Those with prehospital traction splints fitted had fewer units of blood transfused in the first 24 hours and had shorter hospital stays. However, this group had lower ISSs, and we cannot attribute these outcomes to the use of a femoral traction splint. This is the first work to perform follow-up and look at outcomes.

The Oxford Centre for Evidence-Based Medicine describes the quality of evidence in levels from 1 to 5 . Level 1 evidence is a systematic review of randomized, controlled trials and level 5 is expert opinion. ${ }^{10}$ The articles discussed in this study are mostly level 4: single case studies or a review of articles based on single case studies, and many of the articles discussed case studies in which there was poor follow-up or no outcome reviews. This level of evidence can guide our clinical decision making but is not sufficiently robust to define clinical policy. We suggest that if femoral traction splints were introduced today as a new medical device, the current literature would be insufficient to support their use. The conference abstract by Spano et $\mathrm{al}^{25}$ is the first article on traction splints to have a higher level of evidence on which perhaps decisions could be made, although the full article is awaited. We believe that an absence of evidence does not mean that there is an absence of effect, and it remains possible that this is an effective device, but that more research is required to demonstrate any benefits. We failed to find high-quality evidence to support the hypothesis that traction splints reduced morbidity and mortality of femur fractures.

In the context of mountain rescue and other situations of prehospital care, it is reasonable to ask whether other forms of splint may be as effective or superior to the femoral traction splint. At the present time there are no studies on which to base practice.

\section{LIMITATIONS}

The estimated incidence of femur fractures within mountain rescue is based on clinical suspicion of a fracture. True incidence could only be established by recording casualty details and correlating with the results of radiological investigation. However, in prehospital care, treatment is determined by clinical findings and thus this represents real-world practice. The result from the survey assessing attitudes toward traction splints is the summary of the opinions of only 164 mountain rescue individuals. We did, however, manage to capture all areas of England and Wales covered by the MREW teams, as teams are collected into groups to cover different areas and we obtained responses from all groups. Responses were obtained from many of the teams who treat the greatest number of casualties, and therefore we suggest this represents a reasonable picture of current attitudes.

\section{Conclusions}

Femur fractures are rare and traction splints used infrequently in mountain rescue in England and Wales. Mountain rescue team members report few difficulties in use despite their limited practical experience. Current literature evidence suggests that traction splints may be no more beneficial than simple splints in the treatment of femur fractures. Further research is required to compare traction splints with simple splints and to evaluate their contribution in relieving pain, hemorrhage, other complications, and outcome for patients with a fractured femur.

We would suggest the use of a traction splint is reasonable when there is a suitable indication and no contradictions. However, in keeping with the International Commission for Alpine Rescue (ICAR) guidelines, ${ }^{18}$ we accept that other forms of splinting may be equally or even more appropriate in the rescue situation.

\section{Acknowledgments}

Thanks to Dr Karen Greene for her supervision and comments on the project, G. Fenny for data extraction from the MREW database, and Pippa Orr and Kath Johnson for assistance in the literature searches and obtaining articles. Thank you to the members of the MREW teams for completing the questionnaire.

\section{Appendix. Supplementary Materials}

Supplementary material cited in this article is available online at http://dx.doi.org/10.1016/j.wem.2015.01.006.

\section{References}

1. Thomas HO. Diseases of the Hip, Knee and Ankle Joints With Their Deformities: Treated by a New and Efficient Method. Liverpool: T. Dobb \& Co; 1876.

2. Jones R. Correspondence: Treatment of Fractures of the Thigh. BMJ. 1914; Dec 19:1086-1087. 
3. Rudloff MI, Smith WR. Intramedullary nailing of the femur: current concepts concerning reaming. J Orthop Trauma. 2009;23(suppl 5):S12-S17.

4. Prehospital Trauma Life Support Committee of the National Association of Emergency Medical Technicians with the Committee on Trauma of the American College of Surgeons. Prehospital Trauma Life Support. 7th ed. Elsevier Mosby; 2010:342.

5. Greaves I, Porter K, Smith J. Practical Prehospital Care: The Principles and Practice of Immediate Care. 1st ed. Edinburgh: Churchill Livingstone Elsevier; 2011:312.

6. Bledsoe GH, Manyak MJ, Townes DA. Expedition and Wilderness Medicine. New York, NY: Cambridge University Press; 2008:654.

7. Ellerton J. Casualty Care in Mountain Rescue. 2nd ed. Mountain Rescue England and Wales; 2006.

8. Johnson C, Anderson S, Dallimore J, Winser S, Warrell DA. Oxford Handbook of Expedition and Wilderness Medicine. New York, NY: Oxford University Press; 2008.

9. Auerback PS. Wilderness Medicine. 6th ed. Philadelphia, PA: Elsevier Mosby; 2012.

10. Oxford Centre for Evidence-Based Medicine. Available at: http://www.cebm.net/category/ebm-resources/tools/. Accessed October 2014.

11. Agrawal Y, Karwa J, Shah N, Clayson A. Traction splint: to use or not to use. J Perioper Pract. 2009;19: 295-298.

12. Watson AD, Kelikian AS. Thomas splint, calcaneus fracture, and compartment syndrome of the foot: a case report. J Trauma. 1998;44:205-208.

13. Mihalko WM, Rohrbacher B, McGrath B. Transient peroneal nerve palsies from injuries placed in traction splints. Am J Emerg Med. 1999;17:160-162.
14. Corea JR, Ibrahim AW, Hegazi M. The Thomas splint causing urethral injury. Injury. 1992;23:340-341.

15. Wood SP, Vrahas M, Wedel SK. Femur fracture immobilization with traction splints in multisystem trauma patients. Prehosp Emerg Care. 2003;7:241-243.

16. Abarbanell NR. Prehospital midthigh trauma and traction splint use: recommendations for treatment protocols. Am J Emerg Med. 2001;19:137-140.

17. Bledsoe B, Barnes D. Traction splints: an EMS relic? JEMS. 2004;29:64-69.

18. Ellerton J, Tomazin I, Brugger H, Paal P, International Commission for Mountain Emergency Medicine. Immobilization and splinting in mountain rescue. High Alt Med Biol. 2009; 10:337-342.

19. Hearns S. The Scottish mountain rescue casualty study. Emerg Med J. 2003;20:281-284.

20. Goel A, Addison AK. Fell walking injuries in Cumbria: a review. Br J Sports Med. 1992;26:143-144.

21. Hohlrieder M, Eschertzhuber S, Schubert H, Zinnecker R, Mair P. Severity and pattern of injury in survivors of alpine fall accidents. High Alt Med Biol. 2004;5:349-354.

22. Gray H. The Early Treatment of War Wounds. London: $\mathrm{H}$ Frowde, Hodder and Stoughton; 1919.

23. Henry BJ, Vrahas MS. The Thomas splint: questionable boast of an indispensable tool. Am J Orthop (Belle Mead NJ). 1996;25:602-604.

24. Rowlands TK, Clasper J. The Thomas splint-a necessary tool in the management of battlefield injuries. J R Army Med Corps. 2003;149:291-293.

25. Spano S, Campagne D, Cagle K, Weichenthal L, Young M, Anastopoulos PH. Prehospital midthigh trauma and traction splint use: a retrospective review of a trauma registry (SAEM Abstract). Acad Emerg Med. 2014;21(suppl 1):S75-S76. 